\title{
Crack Arrestability Test for Extremely Long Brittle Cracks in Thick Steel Plates*
}

\section{Introduction}

The crack arrestability of thick steel plates for large structures such as LPG and LNG storage tanks is one of the most important properties of steel against catastrophic brittle fracture. The test introduced here simulates of an extremely long brittle crack propagation in real structures, and it is sometimes carried out in Japan to investigate the crack arrestability of thick steel plates.

\section{Test Procedures}

An example of the test arrange$3 \mathrm{~m}$ wide and $3.3 \mathrm{~m}$ long. It is socalled hybrid double tension specimen which is constructed by welding. The specimen is pulled by a large-capacity test rig. At the top of the specimen, a crack initiation part is located. After the specimen is loaded, a brittle crack is initiated and propagates in the upper half of the specimen, where a comparatively brittle material is used. The crack acrosses a weld and intrudes to the lower half of the specimen, where the test material is used. If the test material has enough crack arrestability, the otherwise the crack goes all through

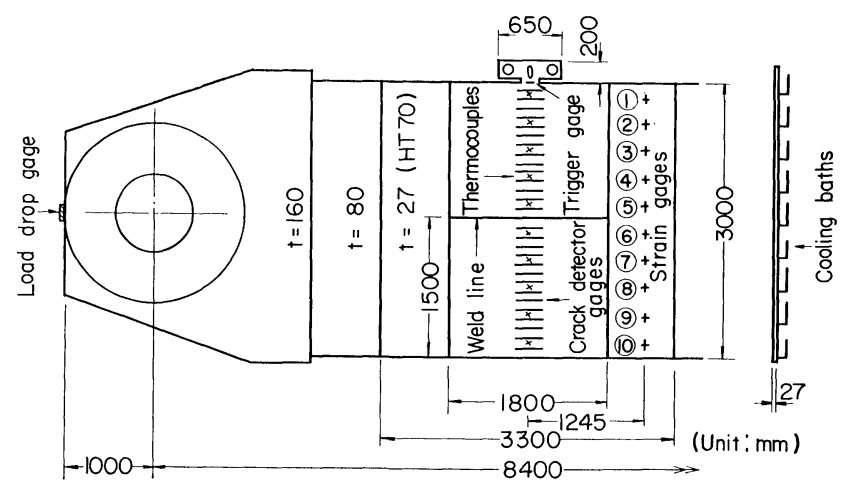

Fig. 1. Arrangement of crack arrestability test to extremely long brittle crack. tion. ${ }^{1,2)}$ length ment is shown in Fig. 1.1,2) The specimen located in the center is crack is arrested in the material and

the specimen. Many thermocouples, crack detector gages and strain gages are mounted as shown in Fig. 1. The temperature distribution, the crack velocity, and the dynamic load drop and strain change during the crack propagation are measured by them.

Figure 2 shows an example of the crack arrestability of a $9 \% \mathrm{Ni}$ steel plate for LNG storage tanks. The test was carried out at $-162{ }^{\circ} \mathrm{C}$ and the applied stress was $392 \mathrm{~N} /$ $\mathrm{mm}^{2}$. A brittle crack propagated at $800 \mathrm{~m} / \mathrm{sec}$ in the embrittled steel plate, intruded to the $9 \% \mathrm{Ni}$ steel plate tested and was arrested very shortly. This steel plate has been proved to have enough crack arrestability of an extremely long brittle crack, $1.5 \mathrm{~m}$ in length.

\section{Interpretation of Test Re- sults}

To generalize the test results, a fracture mechanics method is applied. The critical stress intensity factor $K_{\mathrm{c}}$ of the material tested is evaluated by the following equa-

$$
K_{\mathrm{c}}>\sigma_{0} \sqrt{ } \pi c \cdot \frac{P}{P_{0}} \cdot F\left(\frac{C}{B}\right)
$$

$P: \quad$ the load at the moment of intruding to the test material estimated from the compliance of the test rig

$P_{0}$ : the initial load by the test rig

$F(C / B)$ : the correction factor of the stress intensity factor of the finite plate

$B$ : the width of the specimen.

Dynamic analysis of this test is now in arguments. ${ }^{3)}$ Finite-difference or finite-element methods are applied to the test results, and dynamic stress intensity factors can be calculated from the dynamic measurements, which requires the correct and plentiful measurements in the test.

\section{REFERENCES}

1) S. Machida et al.: J. Soc. Naval Architects Japan, 150 (1981), 511.

2) Y. Kawaguchi et al.: Fracture Toughness Testing (held in London), (1982), Paper 6.

3) T. Kanazawa et al.: "Fast Fracture and Crack Arrest" ASTM Spec. Tech. Publ., 627 (1977), 39.

where, $\sigma_{0}:$ the initial stress

$C$ : the intruding crack

\footnotetext{
* For further information, write to Hasaki Research Center, Central Research Laboratories, Sumitomo Metal Industries, Ltd., Hasakimachi, Kashima-gun, Ibaraki 314-02. (C) 1984 ISIJ
} 